\title{
N,O-Carboxymethylchitosan (NO-CMC) and Oligo-Chitosan (O-C) : Scaffold Characterization
}

\author{
Mercy Halleluyah Periayah ${ }^{1}$, Ahmad Sukari Halim ${ }^{1 *}$, Sankaralakshmi Gomathysankar ${ }^{1}$, \\ Amirul Akram Ahmad Sukari ${ }^{1}$, Arman Zaharil Mat Saad ${ }^{1}$, Ahmad Hazri Abdul Rashid ${ }^{2}$, \\ Zanariah Ujang ${ }^{2}$, Noor Zuhartini Mohd Muslim ${ }^{3}$ \\ ${ }^{1}$ Reconstructive Sciences Unit, School of Medical Sciences, Universiti Sains Malaysia, 16150 Kubang Kerian, Kelantan, Malaysia \\ ${ }^{2}$ Industrial Biotechnology Research Centre, SIRIM Berhad, No.1 Persiaran Dato' Menteri Section 2, P.O Box 7035, \\ 40700 Shah Alam, Selangor, Malaysia \\ ${ }^{3}$ Department of Forensic Sciences, School of Health Sciences, Universiti Sains Malaysia, 16150 Kubang Kerian, Kelantan, Malaysia \\ *Corresponding author E-mail: ashalim@usm.my
}

Copyright $\odot 2014$ Periayah et al. This is an open access article distributed under the Creative Commons Attribution License, which permits unrestricted use, distribution, and reproduction in any medium, provided the original work is properly cited.

\begin{abstract}
Chitosan is of great interest because it is biocompatible, biodegradable and abundant in nature. Accurate characterization of modified chitosan biopolymers is essential to optimize their usage. In our present work, we have tested the physicochemical characterization of 4 different types of chitosan biomaterials, which are classified into $N, O$ carboxymethylchitosan (NO-CMC) and Oligo-Chitosan (O-C). We have employed Fourier Transform Infrared Spectroscopy (FTIR) to analyze the functional groups and Scanning Electron Microscopy (SEM) to examine the scaffold membrane properties of each biomaterial. The FTIR analysis confirmed that a large number of alterations were made towards the NO-CMC group of chitosan. Meanwhile, most of the bands observed in the O-C group can generally be found in the standard model of chitosan. Shifting of the carbonyl group is only noticed in O-C group, which distinguishes both chitosan groups at $1644.20-1633.69 \mathrm{~cm}^{-1}$ peak. The NO-CMC and O-C groups, which have compressive porous structures, are able to support tissue and cell adherence via mechanical strength. Chitosan biopolymers, which vary from different grades and forms, are performing best when their unique properties are optimized. Hence, the study of these structurally modified chitosans and their characterization is very important to correlate their usage and properties in various fields.
\end{abstract}

Keywords: N, O-Carboxymethylchitosan (NO-CMC), Oligo-Chitosan (O-C), Functional Group, Morphology, Porosity

\section{Introduction}

Biomaterials can be defined as any nondrug synthetic material that is used to restore, replace or imitate the original processes of damaged tissues and cells [1-2]. Naturally invented biomaterials are rapidly expanding and functioning to fulfill biological and medical necessities. There are various types of biomaterials available in different configurations. Each biomaterial has its own advantages and limitations. An ideal biomaterial must be biocompatible, biodegradable, bioabsorbable, biofunctional, easy to handle, nontoxic, support cell adhesion, nonimmunogenic and low-cost [3]. Recently, considerable attention has been paid to chitosan-derived biomaterials because of the abundance of chitosan in nature, and they are becoming some of the most promising biomaterials for reducing various types of complications upon medical interventions. Chitosan is a polysaccharide that contains $N$-acetyl glucosamine and is obtained from the deacetylation of chitin, which is derived from the exoskeleton of arthropods such as crabs, shrimps, lobsters and insects [4]. Chitosan biomaterials have been shown to exhibit and possess good biocompatibility, antimicrobial activity, biodegradability, hemostatic activity, antioxidant properties and drug delivery abilities [5-9]. Lately, these biomaterials have attracted more interest, and a variety of procedures have been proposed to produce standard modified chitosan biomaterials by altering the structure and the physical and chemical composition of chitosan polymers to generate distinct formulations of chitosan derivatives for various applications in the fields of biotechnology, tissue engineering, cosmetics, biomedicine, food and agriculture [10-13]. The preparation and properties of chitosan biomaterials depend 
on the grade, form, concentration, molecular weight, and degree of deacetylation of the chitosan, as well as the $\mathrm{pH}$, temperature, incubation period and viscosity. Not all biological activities are displayed by one type of chitosan. One of the main characteristics that make chitosan a biocompatible material is that it has a strong positive electrical charge, which strongly attracts and bonds to negatively charged molecules. Fundamentally, chitosan has three different types of reactive functional groups, and the amino groups consists of both primary and secondary hydroxyl groups at the $\mathrm{C}(2)$, $\mathrm{C}(3)$, and $\mathrm{C}(6)$ positions. Each special type of bioactive chitosan has been developed by chemical modification and enzymatic hydrolysis. The amino content is the primary factor resulting in the differences between their structures and physiochemical properties because it correlates with their chelating properties, thereby altering biological functions [14]. Accurate characterization of the functional groups of chitosan biomaterials can be performed using Fourier Transform Infrared Spectroscopy (FTIR), which is an analytical technique used to identify the chemical bonds and composition of biomaterials. Numerous types of scaffolds can be fabricated using chitosan-derived polymers such as sponges, powders, gel sheets, films, microcapsules, fibers and porous structures. Normally, the porosity of a deacetylated chitosan biomaterial, which is measured in diameter $(\mu \mathrm{M})$ and analyzed using scanning electron microscope (SEM), is important to characterize. SEM analysis can be used to demonstrate the construction of a porous network between polymeric scaffolds. Although extensive research and experimentation has been undertaken to elucidate the importance of chitosan biomaterials in various fields, to the best of our understanding, the underlying mechanical pathway that is involved in the characterization of the physical and chemical chitosan biomaterials remains to be explained. Because this characterization framework is questionable, we have proposed in this paper to study the functional groups and scaffold porosity. In our present work, we have tested 4 different types of chitosan biomaterials that can be categorized as N,O-carboxymethylchitosan (NO-CMC) and oligo-chitosan (O-C). These chitosans were produced by the Standard and Industrial Research Institute of Malaysia (SIRIM Berhad). Previously, it has been reported that $\mathrm{O}-\mathrm{C}$ and NO-CMC chitosan derivatives are acceptable because of their mechanical strength and excellent biocompatibility [15]. Our present results produce several noteworthy and quality contributions to increase our understanding of the characterization of NO-CMC and O-C biomaterials and the underlying mechanical principles.

\section{Materials and methods}

\subsection{Materials}

We have tested NO-CMC and O-C chitosans produced by SIRIM Berhad, which were isolated from shrimp shells and had a degree of deacetylation of 75-98\%. The NO-CMC type of chitosans were in sponge, hydrogel-sheet, and porous scaffold forms and were denoted 7\% NO-CMC with $0.45 \mathrm{~mL}$ collagen (7\% NO-CMC), 8\% NO-CMC and NO-CMCGel-Sheet (NO-CMC-GS). Meanwhile, the O-C types of chitosan were in film, sponge and powdered forms, which are denoted O-C-Film (O-C-F), Porous Chitosan Scaffold (PCS), Oligo-Chitosan Sponge (O-CS) and O-C-Powder (O-C 53).

\subsection{Methods}

\subsubsection{FTIR analysis}

Each chitosan biomaterials measured exactly $5 \mathrm{~mm}$ x $5 \mathrm{~mm}$. The characteristic bands of the functional groups were measured according to the wavelength $\left(\mathrm{cm}^{-1}\right)$. All spectra were analyzed using the Attenuated Total Refraction (ATR) method (Bruker Optics Tensor 27 FT-IR Spectrometer, Germany), and the spectra were studied using OPUS 7.0 software. The scans were performed with an average of 16 repeated scans at a $4 \mathrm{~cm}^{-1}$ scan resolution. The spectra were collected in continuous scan mode over a wavelength range of 4000-400 $\mathrm{cm}^{-1}$. Each functional group of the NO-CMC and O-C biomaterials studied was analyzed using the spectroscopic analysis website http://www.science-andfun.de/tools/ [16-18].

\subsubsection{SEM analysis}

Each chitosan biomaterials measuring $5 \mathrm{~mm}$ x $5 \mathrm{~mm}$ was placed in a 12 -well tissue culture plate. Each well was then washed with penicillin-infused PBS for 1 hour, fixed in $100 \mu \mathrm{L}$ of glutaraldehyde for 1 hour, and then washed with distilled water. Different concentrations of ethanol (30\%, $70 \%$ and $100 \%$ ) were added to dehydrate the chitosan biomaterials. Finally, all the samples were dried in an incubator $\left(58^{\circ} \mathrm{C}\right)$, except for NO-CMC-GS and O-C-F, which were dried at room temperature overnight. Once the biomaterials were completely dried, they were subsequently sputter-coated with gold using a gold sputter coater (Leica SCD 005, Germany) [vacuum millibar of 5 x $10^{-2}$; Current 20 milliampere (mA); Timer 150 seconds]. The gold sputtered chitosan biomaterials were examined under SEM (FEIQUANTA FEG 450, Netherlands), and their surface and cross-section morphologies were evaluated [7-8, 19-20]. The Scaffold pore diameter for each biomaterial $(n=3)$ was analyzed and the data presented as the means \pm standard error of means (S.E.M). 


\section{Results}

\subsection{FTIR analysis}
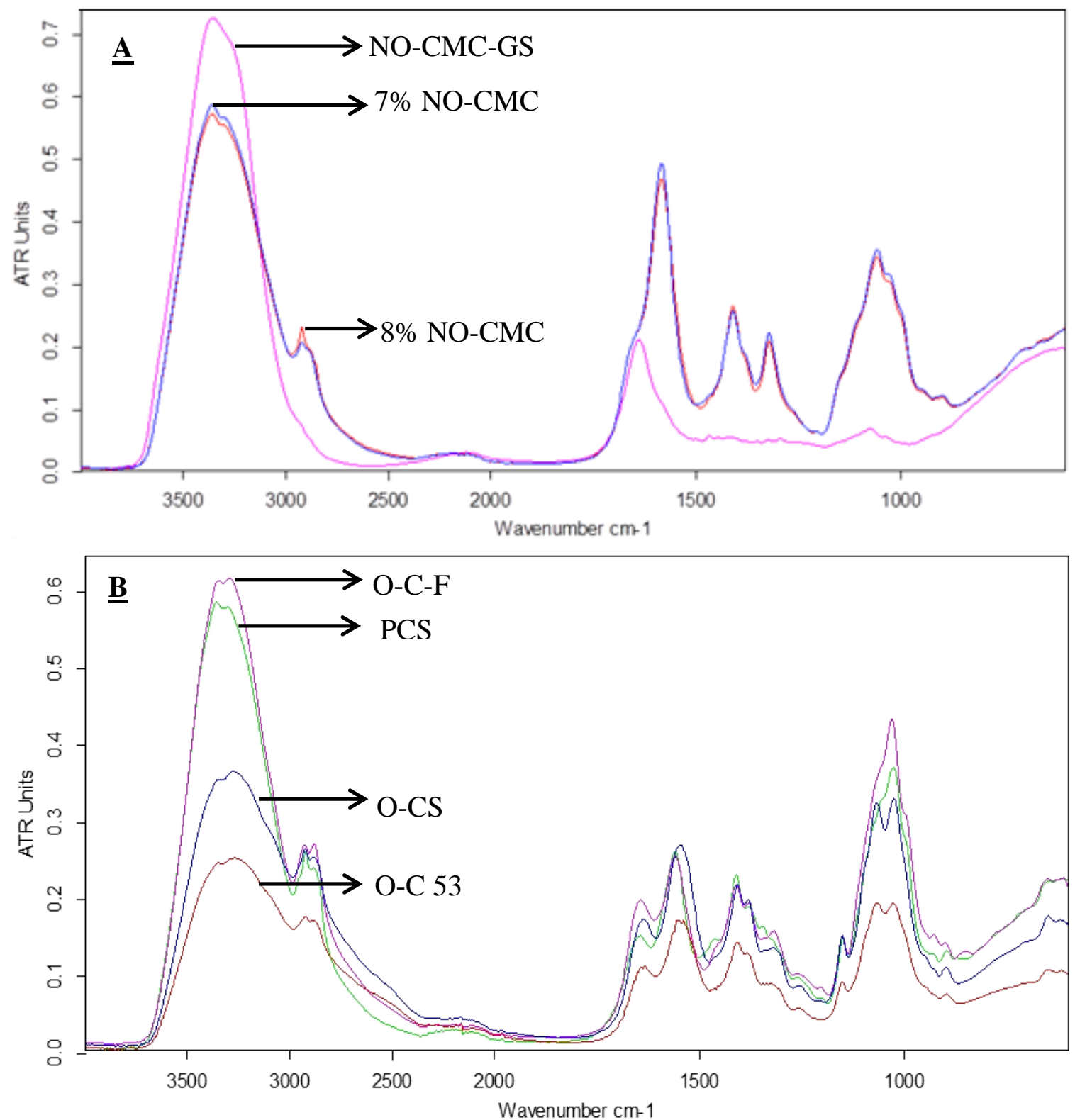

Fig. 1: FTIR Spectra of (A) NO-CMC and (B) O-C. Four different types of chitosan biomaterials were analyzed, and the wavelengths ranged from $4000-400 \mathrm{~cm}^{-1}$

The functional groups of NO-CMC (Figure 1A) and O-C (Figure 1B), which comprise 4 types of chitosan biomaterials, were analyzed using FTIR. The functional groups of both chitosans were classified into 17 different specific groups of atoms and bands within molecules that were particularly responsible for the structure and are involved in the mechanical action of chitosan derivatives. The results of the IR spectra analysis of NO-CMC and O-C, which are summarized in Table 1, were consistent with many of the previously reported studies. A broad absorption band and strong stretch attributed to $-\mathrm{NH}$ and $-\mathrm{OH}$ stretching vibrations were noticed at approximately $3360.10 \mathrm{~cm}^{-1}$ for the NOCMCs. Meanwhile, for the O-C type of chitosan, double stretching of $-\mathrm{NH}$ and $-\mathrm{OH}$ were noticed at approximately $3347.57 \mathrm{~cm}^{-1}-3271 \mathrm{~cm}^{-1}$. Hydrogen molecular bonding was also observed internally and externally in the chitosan molecules. Based on the FTIR analysis, most functional groups are absent for the NO-CMC type of chitosans in comparison to the O-C type. A sharp and intense peak occurred for all the tested biomaterials except for NO-CMC-GS from approximately $1583.67 \mathrm{~cm}^{-1}$ to $1549.32 \mathrm{~cm}^{-1}$, indicating the bending vibration of an amide II stretch. The intensity of the carbonyl group was only noticed in the O-C group of chitosan as a peak at $1644.20-1633.69 \mathrm{~cm}^{-1}$. Subsequently, the $\mathrm{C}-\mathrm{O}$ vibration in the primary $\mathrm{OH}$ group was recorded as the third highest peak within the range of $1057.43 \mathrm{~cm}^{-1}$ to 
$1026.18 \mathrm{~cm}^{-1}$. It is worth noting that many modifications have been done on the O-C type of chitosans, which contain $90 \%$ of the 17 types of functional groups listed in Table 1 . The absorption bands detected within the $1407.11 \mathrm{~cm}^{-1}$ to $608.92 \mathrm{~cm}^{-1}$ regions confirmed that all of the $\mathrm{O}-\mathrm{C}$ group of chitosans had $\mathrm{CH}_{3}, \mathrm{CH}_{2}$ and $\mathrm{CH}$ groups and $1^{\circ}$ and $2^{\circ} \mathrm{OH}$ groups attached to the pyranose ring, as well as oxygen atoms in ether groups.

Table 1: Shows the characteristic absorption bands in the FTIR Spectra of the O-C and NO-CMC groups, which comprise 4 different types of chitosan biomaterials. The wavelength ranges were $4000-400 \mathrm{~cm}^{-1}$. [v = vibration; ${ }_{\text {asvm }}=$ asymmetrical; ${ }_{\mathrm{svm}}=$ symmetrical; pyranose $=$ chemical structure that consists of a six-membered ring containing five carbon atoms and one oxygen atom; $\mathrm{d}=$ deformation; $\mathrm{O}-\mathrm{H}=$ hydrogen bond; $\mathrm{NH} \& \mathrm{NHCO}=$ peptide bond $/$ amide; $\mathrm{CH}_{2}=$ carbine / methylene $\mathrm{C}-\mathrm{H}=$ carbon-hydrogen bond; $\mathrm{C}-\mathrm{C}=$ carbon-carbon; $\mathrm{C}=\mathrm{O}=$ carbon-oxygen; $\mathrm{NHCOCH}_{3}=$ attached from the $\mathrm{N}$ to a benzene ring $\left(\mathrm{C}_{6} \mathrm{H}_{5}\right)$; Amide = conjugate base of ammonia; $\mathrm{CH}_{2} \mathrm{OH}=$ hydroxymethyl group; $\mathrm{CH}_{3}=$ methyl group; $\mathrm{NH}_{3}=$ Ammonia; $\mathrm{C}-\mathrm{O}-\mathrm{C}=$ hydroxyl group of chitosan; glycosidic linkages $=$ covalent linkages that join the carbohydrate molecules with another group; $2^{\circ}=$ secondary; $1^{\circ}=$ primary; out of plane $=$ type of bend that can be scissoring similar to blades / rocking, where two atoms actually move in the same direction]

\begin{tabular}{|c|c|c|c|c|c|c|c|}
\hline & & \multicolumn{6}{|c|}{ Wavelength $\left(\mathrm{cm}^{-1}\right)$} \\
\hline & & $\begin{array}{c}7 \% \text { NO- } \\
\text { CMC \& } \\
8 \% \text { NO- } \\
\text { CMC }\end{array}$ & $\begin{array}{c}\text { NO- } \\
\text { CMC-GS }\end{array}$ & O-C-F & PCS & O-CS & O-C 53 \\
\hline 1 & $\mathrm{v}(\mathrm{O}-\mathrm{H}, \mathrm{N}-\mathrm{H})$ stretch & 3360.79 & 3360.10 & $\begin{array}{c}3347.57- \\
3296.80\end{array}$ & $\begin{array}{l}3359.25- \\
3201.47\end{array}$ & $\begin{array}{c}3348.73- \\
3275.56\end{array}$ & $\begin{array}{c}3345.38- \\
3271.44\end{array}$ \\
\hline 2 & $\begin{array}{c}\mathrm{v}_{\text {asy }}\left(\mathrm{CH}_{2}\right) \text { in } \mathrm{CH}_{2} \mathrm{OH} \\
\text { group }\end{array}$ & 2920.52 & - & 2928.04 & 2921.81 & 2924.45 & 2925.81 \\
\hline 3 & $\mathrm{v}(\mathrm{C}-\mathrm{H})$ in pyranose ring & - & - & 2881.57 & 2883.99 & 2882.31 & 2883.04 \\
\hline 4 & $\mathrm{CN}$ stretch & 2144.99 & 2136.20 & 2163.53 & - & 2162.93 & 2162.88 \\
\hline 5 & $\mathrm{v}(\mathrm{CC})$ & - & - & 2085.39 & - & - & 2086.72 \\
\hline 6 & $\begin{array}{l}\mathrm{v}(\mathrm{C}=\mathrm{O}) \text { in } \mathrm{NHCOCH}_{3} \\
\text { group (Amide I band) }\end{array}$ & - & - & 1643.74 & 1644.20 & 1637.62 & 1633.69 \\
\hline 7 & $\begin{array}{l}\text { Amide II N-H stretch / } \\
\mathrm{NH}_{3}^{+}\end{array}$ & 1583.67 & - & 1557.97 & 1557.89 & 1544.80 & 1549.32 \\
\hline 8 & $\mathrm{q}\left(\mathrm{CH}_{2}\right)$ in $\mathrm{CH}_{2} \mathrm{OH}$ group & 1409.41 & 1466.81 & 1409.80 & 1410.10 & 1407.11 & 1407.71 \\
\hline 9 & $\underset{\text { group }}{\mathrm{c}_{\text {sym }}\left(\mathrm{CH}_{3}\right) \text { in } \mathrm{NHCOCH}_{3}}$ & 1321.80 & - & 1379.26 & 1380.30 & 1380.55 & 1384.00 \\
\hline 10 & $\mathrm{~d}(\mathrm{C}-\mathrm{H})$ in pyranose ring & - & - & 1318.51 & - & 1321.02 & - \\
\hline 11 & $\begin{array}{l}\text { Complex v(NHCO) group } \\
\text { (Amide III band) }\end{array}$ & - & 1294.92 & 1261.08 & 1260.66 & 1256.81 & 1257.43 \\
\hline 12 & $\begin{array}{l}\mathrm{V}_{\text {sym/ asym }}(\mathrm{C}-\mathrm{O}-\mathrm{C}) \\
\text { glycosidic linkage }\end{array}$ & - & - & 1151.21 & 1149.46 & 1151.40 & 1151.63 \\
\hline 13 & $\mathrm{v}(\mathrm{C}-\mathrm{O})$ in $2^{\circ} \mathrm{OH}$ group & - & 1075.12 & - & - & 1067.15 & 1065.92 \\
\hline 14 & $\mathrm{v}(\mathrm{C}-\mathrm{O})$ in $1^{\circ} \mathrm{OH}$ group & 1057.43 & - & 1030.29 & 1026.39 & 1025.01 & 1026.18 \\
\hline 15 & Pyranose ring skeletal(v) & 898.84 & - & $\begin{array}{c}927.29- \\
899.64\end{array}$ & 895.47 & 898.10 & 897.10 \\
\hline 16 & $\mathrm{~d}(\mathrm{NH})$ out of plane & - & - & 650.26 & 649.18 & 648.66 & 650.26 \\
\hline 17 & $\mathrm{~d}(\mathrm{OH})$ out of plane & - & - & 611.20 & 608.92 & 618.34 & 617.03 \\
\hline
\end{tabular}

\subsection{SEM analysis}

The scaffold morphology characterization of NO-CMCs was performed using SEM under magnification ranging from 1000x to 10000x. This analysis confirmed that both the modified 7\% and 8\% NO-CMC sponges, which appears light yellow in color, have different pore sizes. The scaffolds composed layer-by-layer varied in size. Upon macroscopic evaluation, the $8 \%$ NO-CMC seemed to be harder than the $7 \%$ NO-CMC, although the width $(0.8 \mathrm{~mm})$ of both sponges was the same. NO-CMC-GS appeared light brown in color and was only $0.2 \mathrm{~mm}$ wide. A microscopic view showed that the surface morphology of the gel-like NO-CMC appeared similar to sloppy fabric. Only thick curved lines in asymmetrical positions were observed (Figure 2). 


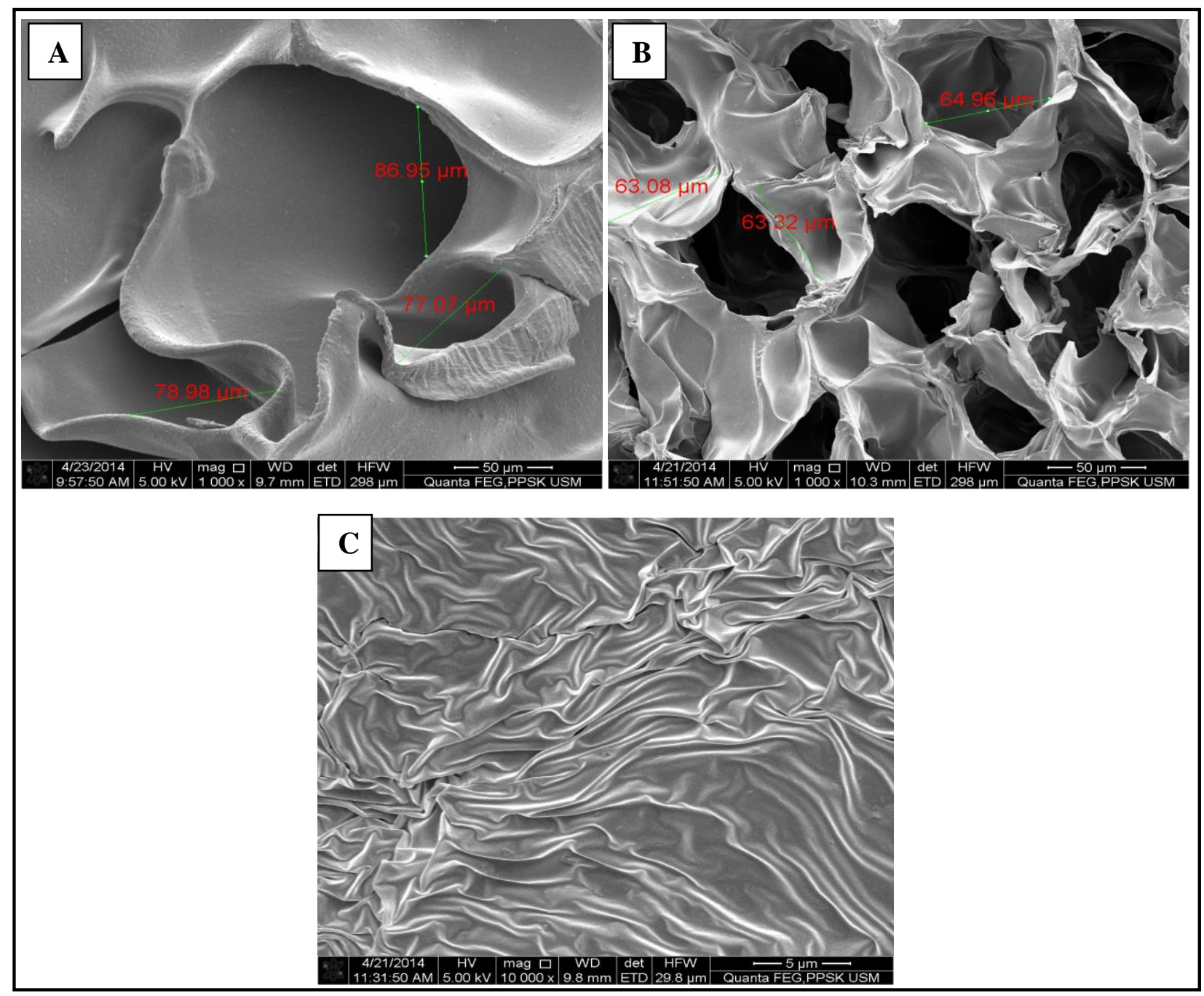

Fig. 2: SEM images of cross-sectional views of chitosan scaffolds [(A) 7\% NO-CMC, (B) 8\% NO-CMC, and (C) NO-CMC-GS]

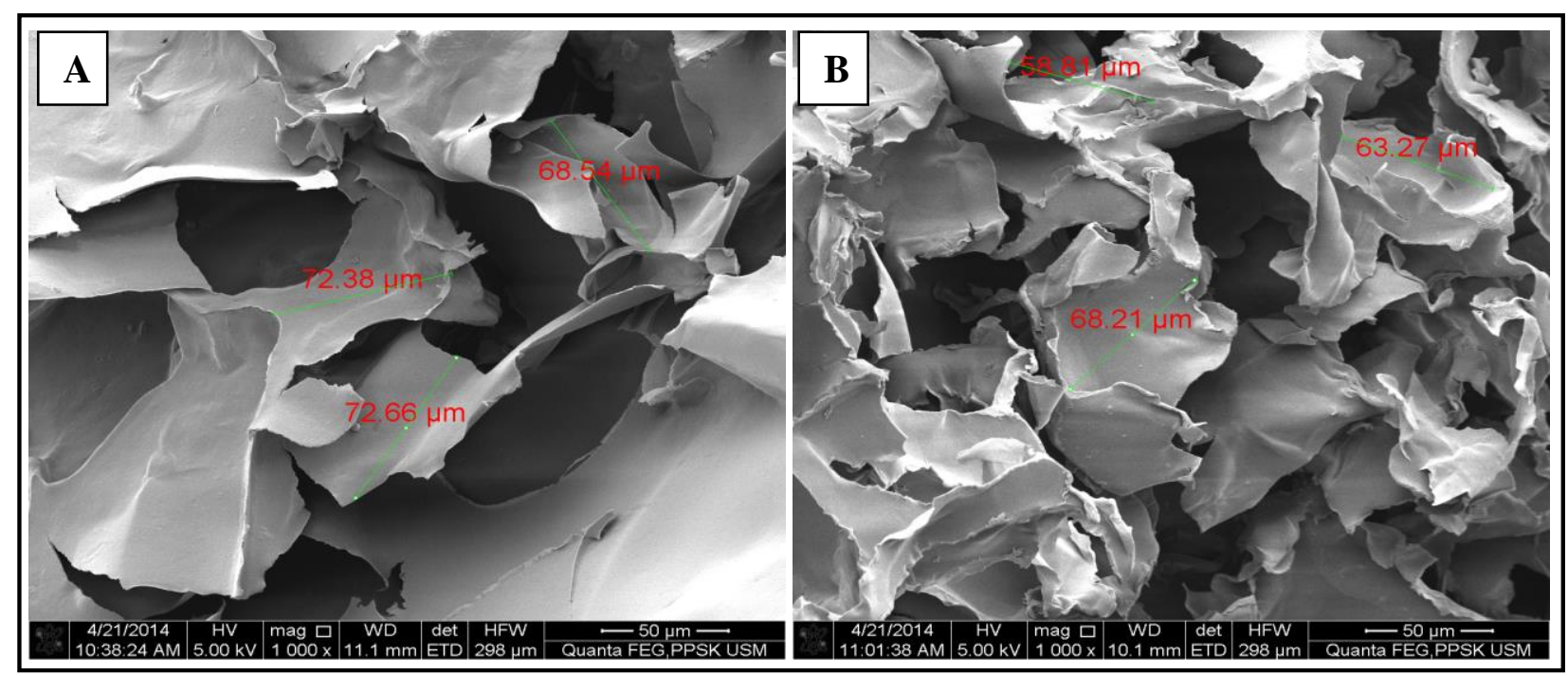




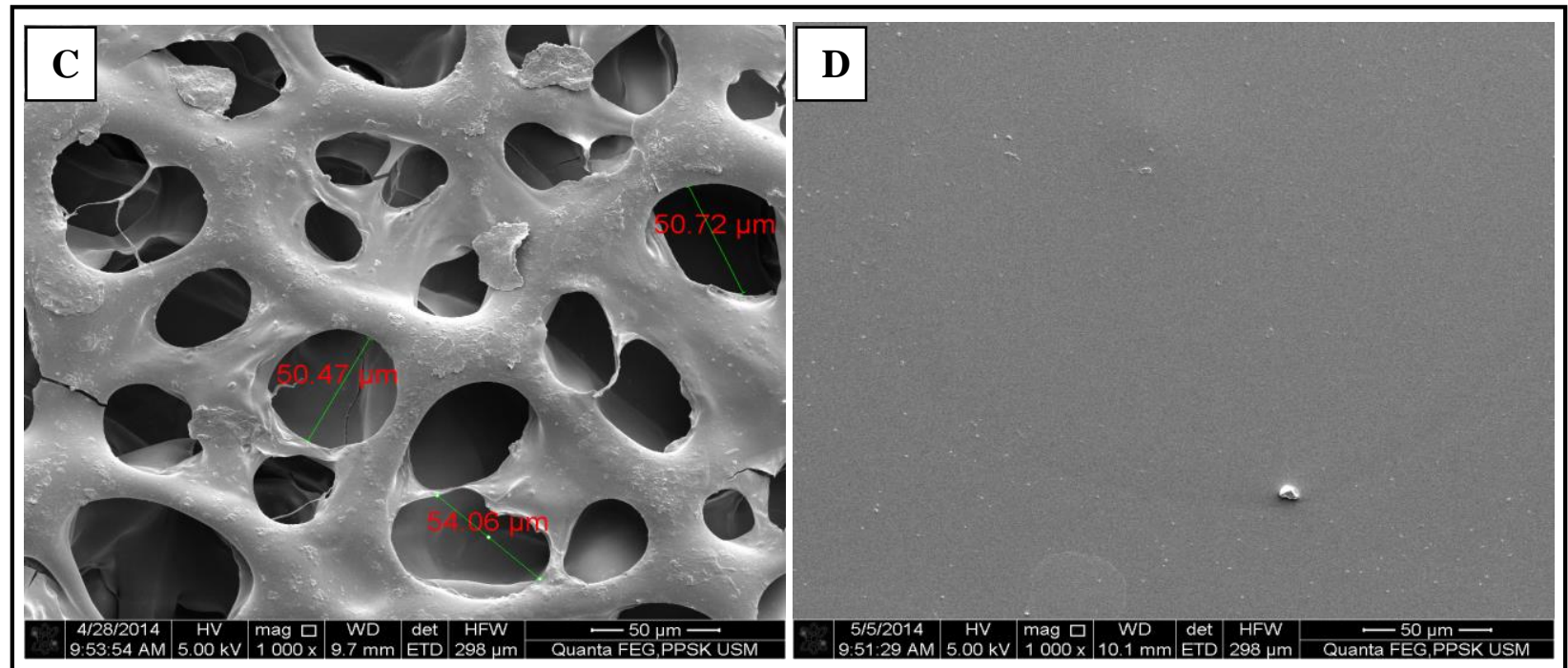

Fig. 3: SEM images of each O-C type of chitosan biomaterials [(A) O-C, (B) O-C 53, (C) PCS, and (D) O-C-F]

The morphology of the O-C group of chitosans was characterized by SEM at a magnification power of 1000x. The scaffold porosity and surface appearances of each type of $\mathrm{O}-\mathrm{C}$ chitosan scaffolds were typically different in diameter, distribution and orientation. OC-S and OC-53 were brown-like, sponge and powdered types of chitosans. The scaffold view of the OC-S biomaterial shows that the layers were compiled in an orderly manner (Figure 3A). Conversely, the scaffold layers for OC-53 were compiled in crowded positions because it is a powdery-type complex matrix (Figure 3B). The scaffolds of PCS biomaterial were in round oval shapes, interconnected with a thick fibrin-like surface material. O-C-F resembled a clear view of a surface membrane without any pores. This film-formed biomaterial differs from other type of O-C because it is made from a brown oily sheet-like material (Figure 3C \& 3D).

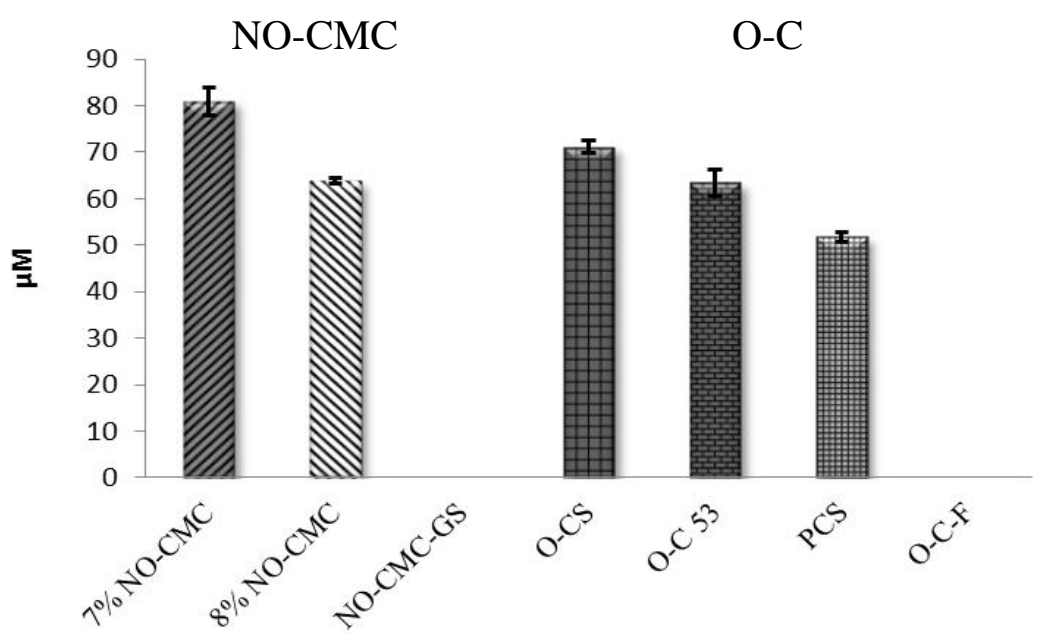

Fig. 4: Scaffold diameter for the 7\% NO-CMC, 8\% NO-CMC, NO-CMC-GS, O-CS, O-C 53, PCS, and O-C-F experimental groups were examined by SEM. A comparison of the Scaffold Porosity $(\mathrm{N}=3)$ was analyzed and the data presented are the Mean \pm S.E.M

Based on the microscopic evaluation, we calculated the pore sizes for each of the chitosan biomaterials. The size of the scaffold porosity highly influences the biocompatiblity and biodegradability of chitosan biomaterials. The highest level of porosity was achieved by $7 \%$ NO-CMC $(81 \pm 3.03 \mu \mathrm{M})$, which was $12.1 \%$ different compared to the O-CS group $(71.18 \pm 1.32 \mu \mathrm{M})$. The $8 \% \mathrm{NO}-\mathrm{CMC}$ and O-C 53 were recorded to have pores with approximately the same diameter $(63.78 \pm 0.59 \mu \mathrm{M}$ and $63.43 \pm 2.71 \mu \mathrm{M}$, respectively). The PCS biomaterial had the lowest level of porosity (only 51.75 $\pm 1.16 \mu \mathrm{M})$. The NO-CMC-GS and O-C-F did not have any pores or scaffolds and appeared as clear surface membranes (Figure 4). 


\section{Discussion}

The development of chitosan-derived biomaterials and their unique properties of being biocompatible, biodegradable and non-toxic have led to considerable attention being focused on their innovative use in modern medicine. Chitin with a degree of deacetylation of $75 \%$ or above is generally known as chitosan [21]. Recently, many ongoing scientific studies have investigated the modification of these chitosan biomaterials to yield polymer blends, which are constructed with desired structures, mechanical properties and chemical characteristics [22]. Generally, the optimal chitosan production comprises 4 major steps: deproteinization, demineralization, decolorization and deacetylation [23]. The molecular weight and degree of deacetylation are the two important features influencing the characteristics of chitosan biomaterials. The deacetylation process mainly involves the removal of acetyl groups from the molecular chains of chitin, which leaves a complete amino group (-NH2). The versatility of chitosan depends highly on the chemically reactive amino groups. In the present, we have investigated the physicochemical characterization of sponge, powder, gel-sheet and film-type chitosan biomaterials. We have employed FTIR to analyze the functional groups and SEM to examine the scaffold membrane properties of chitosan-derived biomaterials. IR spectroscopy is the most discussed technique in the literature because it is simple to use and easy to calibrate. Regardless of the degree of acetylation, the source, the availability or the solubility of the chitosan biopolymer, IR spectroscopy analysis aids in identifying the chemical composition of modified chitosan biopolymers. In addition, calibration with different ratios of chitin and chitosan representatives with their respective deacetylation values can be performed [24]. This FTIR analysis should clearly give a linear relationship for the characteristic N-acetyl substitution band. FTIR spectra are usually recorded in the middle IR, with a wavelength range of 4000-400 $\mathrm{cm}^{-1}$, along with a resolution of $4 \mathrm{~cm}^{-1}$ in the absorbance mode for 8 to 128 scans at room temperature [25]. In this study, the scans were performed with an average of 16 repeated scans at a $4 \mathrm{~cm}^{-1}$ scan resolution. The spectra were collected in continuous scan mode over a wavelength range of $4000-400 \mathrm{~cm}^{-}$ ${ }^{1}$. The absorption band and the significant peaks for each functional group of the chitosan biomaterials were classified into 17 different groups, as shown in Table 1. We noticed broad absorption band and a strong single stretch attributed to $-\mathrm{NH}$ and $-\mathrm{OH}$ stretching vibrations at approximately $3360.10 \mathrm{~cm}^{-1}$ for NO-CMCs and double stretching of $-\mathrm{NH}$ and $\mathrm{OH}$ for the O-C group of chitosans at approximately $3347.57 \mathrm{~cm}^{-1}-3271 \mathrm{~cm}^{-1}$. The presence of the methyl group in $\mathrm{NHCOCH}_{3}$, the methylene group in $\mathrm{CH}_{2} \mathrm{OH}$ and the methyne group in the pyranose ring was shown by the corresponding stretching vibrations for both groups of chitosans in the range of $2920.52-2881.57 \mathrm{~cm}^{-1}$. The band noticed at $1583.67-1544.80 \mathrm{~cm}^{-1}$ was for all the tested chitosans except for NO-CMC-GS, which had a larger intensity, indicating the presence of chitosan with effective deacetylation. The peak present at these points also suggested the prevalence of $\mathrm{NH}_{2}$ groups. The Amide $\mathrm{I}$ is engaged with the occurrences of internal hydrogen molecular bonds of the type $\mathrm{C}=\mathrm{O} \ldots \mathrm{HN}$ and the intramolecular hydrogel bonds, such as $\mathrm{C}=\mathrm{O} \ldots \mathrm{HOCH}_{2}$ [24,26-27]. A doublet mode of the Amide I band exists in standard chitin models, which proves the increased levels of morphological arrangement or high order crystallinity [17]. Our experimental results suggest that the second band (Amide II) which was located at 1583.67 $-1544.80 \mathrm{~cm}^{-1}$ interval, corresponds to trans-secondary amides, depending on the intermolecular levels associated between the $\mathrm{C}=\mathrm{O}$ and $\mathrm{N}-\mathrm{H}$ groups. The $\mathrm{O}-\mathrm{C}$ group of chitosans showed absorption bands at the wavelength range of $1644.20-1633.69 \mathrm{~cm}^{-1}$, which is a gradual shift in the $\mathrm{C}=\mathrm{O}$ peaks and was assigned to the $\mathrm{N}-\mathrm{H}$ bending mode of the $\mathrm{NH}_{2}$ and amide I band, respectively [28]. The characteristic bands that occurred at amide I and II represented the presence of $\mathrm{N}$-acetylation [29-30]. The absorption bands detected for the O-C group of chitosans were between 1407.11 $\mathrm{cm}^{-1}$ to $608.92 \mathrm{~cm}^{-1}$, a region that was found to be saturated, due to the distinct vibration modes of $\mathrm{CH}_{3}, \mathrm{CH}_{2}$ and $\mathrm{CH}$ groups and the $1^{\circ}$ and $2^{\circ} \mathrm{OH}$ groups, which are attached to the pyranose ring, and the oxygen atoms in ether groups [31]. We have noticed that, the functional groups presented in the O-C group of chitosans approximately mimic the standard types of chitosan [17]. NO-CMC chitosan was found to be absent of many functional groups following significant alterations and the deletion of chemical structures. In addition, upon modification, 7\% NO-CMC was coated with $0.45 \mathrm{~mL}$ of ovine collagen and in our recent research we have reported that collagen coated $7 \% \mathrm{NO}-\mathrm{CMC}$ are capable of initiating platelet aggregation in vitro by expediting the hemostasis process [8]. In our previous studies, all the examined biomaterials were found to exhibit significant outcomes towards hemostasis, platelet signaling and wound healings. The scaffold properties and morphological views of the chitosan biomaterials characterized by SEM and porosity size in mean \pm S.E.M. The porosity size is very important for cell proliferation and migration when cells are seeded onto chitosan scaffolds because of cell-cell and cell-extracellular matrix interactions. The SEM analysis, therefore, helps in analyzing the structure of chitosan scaffolds to assess their biocompatibility for improved understanding of cell morphology, attachment, proliferation and viability. The SEM images showed microstructures with well interconnected pores. The standard size of the chitosan scaffold obtained from shrimps was $4.50 \pm 0.40$ millimeter $(\mathrm{mm})$ in thickness and $24.2 \pm 1.0 \mathrm{~mm}$ in diameter. The pore size of the chitosan scaffold was $64 \pm 20 \mu \mathrm{M}$ for chitosan derived from the exoskeleton of shrimps. In our study, the mean diameter pores on the entire chitosan scaffold ranged from $50-90 \mu \mathrm{m}$. Polygonal pores and elongated pores were observed randomly in the chitosan samples. The pore diameter of the scaffold is important for studying the biological properties such as biocompatibility and biodegradability [32]. Based on the pore diameter values, the porosity of 7\% NO-CMC was greater than all the other modified chitosan biopolymers. Among them, PCS had the smallest pore diameter and NO-CMC-GS and O-C-F had no pores at all. Because many studies have been successfully conducted and published using both NO-CMC and O-C group, we truly believe that the pore size and the morphology are well accepted to assist in tissue engineering and in 
other pharmaceutical related fields. The scaffold pores are sufficient to allow for nutrients and cells to enter and to encourage cell growth, cell migration, cytokine release and to discharge important metabolic products secreted from cells and encourage oxygen permeability [5-6, 8, 15, 33]. For larger pore sizes, the ability to promote cell attachment tends to decrease because of the complete removal of cells during the washing procedures [34]. Although NO-CMC-GS and $\mathrm{O}-\mathrm{C}-\mathrm{F}$ were noted to be free of pores, they have been reported to be safe for use as wound healing biomaterials in vivo. Both of these biomaterials tested negative for skin corrosion and irritation when evaluated in animal studies. In addition, throughout the study, no remarkable clinical signs or symptoms during the treatment were attributed to the adherence of NO-CMC-GS and O-C-F (unpublished source). Therefore, in the case of this scenario, the integration of the functional groups, structure and the scaffold pore size of chitosan biomaterials typically influence the biological responses. NO-CMC or O-C group of chitosan, which consist of compressive porous structures that are able to support tissue and cell adherences via mechanical strength.

\section{Conclusion}

The relative properties of chitosan that was extracted from shrimp cells were determined. The functional groups and the scaffold properties of NO-CMC and O-C groups of chitosan biomaterials are well pronounced and clearly elucidated in this study. FTIR analysis confirmed that a large number of alterations were made in the NO-CMC group of chitosans. Meanwhile, most of the bands observed in the O-C group can be generally found in a standard model of chitosan. Our present study, however, makes several noteworthy contributions to a growing body of literature on the underlying scaffold characteristics, specifically the pore size and distribution in NO-CMC and O-C. There is growing interest in the chemical modification of chitosans to improve their solubility, absorption, degradation rate, porosity, toxicity level and swelling ratio for better application in biopharmaceutical field. It is recommended that further experimental investigations be undertaken to compare the NO-CMC and O-C groups of chitosans extracted from the exoskeletons of crab and lobster. The obtained results should be compared with the significant outcomes of the present study, which was done to characterize shrimp-extracted NO-CMC and O-C chitosan biomaterials.

\section{Acknowledgements}

This project was financially supported by Universiti Sains Malaysia Research Grant (RU) 1001/PPSP/813068. We would also like to thank Mr. Baharudin Zakaria and Mr. Mohd Anizan Bakhtiar Abdullah from PPSK (USM) who assisted us in FTIR and SEM analysis.

\section{Competing Interests}

The authors have declared that no competing interest exists.

\section{References}

[1] C.M. Agrawal, Reconstructing the Human Body Using Biomaterials. JOM, (1998) 31-35. http://dx.doi.org/10.1007/s11837-998-0064-5.

[2] A. F. Von Recum, M. LaBerge, Educational goals for biomaterials science and engineering: prospective view, J. Appli. Biomater. 6 (1995) 137-144. http://dx.doi.org/10.1002/jab.770060209.

[3] Y. Cao, B. Wang, Biodegradation of silk biomaterials, Int. J. of Mol. Sci. 10 (2009) 1514-1524. http://dx.doi.org/10.3390/ijms10041514.

[4] S.S. Koide, Chitin-chitosan: properties, benefits and risks, Nut. Res. 18 (1998) 1091-1998. http://dx.doi.org/10.1016/S0271-5317 (98)000918 .

[5] L.C. Keong, A.S. Halim, In vitro biocompatibility assessment for biomedical-grade chitosan derivatives in wound management. Int. J. Mol. Sci. 10 (2009) 1300-1313. http://dx.doi.org/10.3390/ijms10031300.

[6] C.K Lim. A.S. Halim, N.S Yaacob et al., The in vitro biocompatibility of chitosan porous skin regenerating templates (PSRTs) using primary human skin keratinocytes. Toxicol. In Vitro. 24 (2010) 721-727.

[7] Y. Okamoto, R. Yano, K. Miyatake et al., Carbohyd. Polym. 53 (2003) 337-342. http://dx.doi.org/10.1016/S0144-8617 (03)00076-6.

[8] M.H. Periayah, A.S. Halim, A.R. Hussein et al., In vitro capacity of different grades of chitosan derivatives to induce platelet adhesion and aggregation, Int. J. of Bio. Macromol. 52 (2013) 244-249. http://dx.doi.org/10.1016/j.ijbiomac.2012.10.001.

[9] M.E.I. Badawy, E.I. Rabea, A biopolymer chitosan and its derivatives as promising antimicrobial agents against plant pathogens and their applications in crop protection, Int. J. Carbohyd. Chemis. 29 (2011).

[10] Y. Huang, S. Onyeri, M. Siewe et al., In vitro characterization of chitosan-gelatin scaffolds for tissue engineering, Biomater. 26 (2005) 76167627. http://dx.doi.org/10.1016/j.biomaterials.2005.05.036.

[11] I. Aranaz, M. Mengíbar, R. Harris et al., Functional characterization of chitin and chitosan. Curr. Chem. Bio. 3 (2009) 203-230.

[12] K. Kurita, Controlled functionalization of the polysaccharide chitin, Progr. Polym. sci. 26 (2001) 1921-1971. http://dx.doi.org/10.1016/S0079. $.6700(01) 00007-7$

[13] M. Werle, A. Bernkop-Schnürch, Thiolated chitosans: useful excipients for oral drug delivery, J. Pharm. and Pharmaco. 60 (2008) 273-281. http://dx.doi.org/10.1211/jpp.60.3.3001.

[14] W.S. Xia, Physiological activities of chitosan and its application in functional foods, J. Chi. Ins. of Food. Sci. and Tech. 3 (2003) 77-81.

[15] B.M Syaiful, A.S. Halim, H. Kamaruddin et al., In vitro evaluation of novel chitosan derivatives sheet and paste cytocompatibility on human dermal fibroblasts, Carbohydr. Polym. 79 (2010) 1094-1100. http://dx.doi.org/10.1016/j.carbpol.2009.10.048

[16] C.A.R. Duarte, J. F. Mano, R. L. Reis, Novel 3D scaffolds of chitosan-PLLA blends for tissue engineering applications: Preparation and characterization, The J. of Supercritical. Fluids. 54 (2010) 282-289. 
[17] D. Zvezdova, Synthesis and characterization of chytosan from marine sources in Black Sea, Annual Proceedings, "Angel Kanchev" University of Ruse, 49, (9.1), (2010), 65 - 69. Access via: http://conf.uni-ruse.bg/bg/docs/cp10/9.1/9.1-11.pdf.

[18] Spectroscopic tools- science and fun. (2014) Access via : http://www.science-and-fun.de/tools/

[19] S.E. Maurer, G. Pfeiler, N. Maurer et al, Room temperature activates human blood platelets, Lab. Invest. 81 (2001) 581-592. http://dx.doi.org/10.1038/labinvest.3780267.

[20] J. Yang, F. Tian, Z. Wang et al., Effect of chitosan molecular weight and deacetylation degree on hemostasis, J. of Biomedic. Mater. Res. Part B: Appli. Biomater. 84B (2007) 131-137. http://dx.doi.org/10.1002/jbm.b.30853.

[21] J. Li, J.F. Revol, R. Marchessault, Effect of degree of deacetylation of chitin on the properties of chitin crystallites, J. of Appli. Polym. Sci. 65 (1997) 373-380. http://dx.doi.org/10.1002/(SICI)1097-4628(19970711)65:2<373::AID-APP18>3.0.CO;2-0.

[22] M.G. Peter, Applications and environmental aspects of chitin and chitosan, J. Macromol. Sci. Part A, (1995) 629-640.

[23] H.K. No, M.Y. Lee, Isolation of chitin from crab shell waste. J. Korean. Soc. Food. Nutr. 24 (1995) $105-113$.

[24] Y. Shigemasa, H. Matsuura, H. Sashiwa, et al., Evaluation of different absorbance ratios from infrared spectroscopy for analyzing the degree of deacetylation in chitin. Int. J. of Bio. Macromol. 18 (1996) 237-42. http://dx.doi.org/10.1016/0141-8130 (95)01079-3.

[25] J. Kumirska, M. Czerwicka, Z. Kaczyński et al., Application of spectroscopic methods for structural analysis of chitin and chitosan, Mar. Drugs. 8 (2010) 1567-1636. http://dx.doi.org/10.3390/md8051567.

[26] J. Brugnerotto, J. Lizardi, F.M. Goycoolea et al., An infrared investigation in relation with chitin and chitosan characterization, Polym. 42 (2001) 3569-3580. http://dx.doi.org/10.1016/S0032-3861 (00)00713-8.

[27] B. Furniss, A. Hannaford, P. Smith et al., Text Book of Practical Organic Chemistry, Longman Scientific and Technical, Harlow, 5 (1989) 695-698.

[28] F. Tian, Y. Liu, K. Hu et al., Study of the depolymerization behavior of chitosan by hydrogen peroxide, Carbohydr. Polym. 57 (2004) $31-37$. http://dx.doi.org/10.1016/j.carbpol.2004.03.016.

[29] G.K. Moore, G.A.F. Roberts, Determination of the degree of N-acetylation of chitosan, Int. J.Biol. Macromol. 2 (1980) 115-116. http://dx.doi.org/10.1016/0141-8130 (80)90040-9.

[30] J.G. Domszy, G.A.F. Roberts, Evaluation of infrared spectroscopic techniques for analyzing chitosan, Die. Makromolekulare. Chemie. 186 (1985) 1671-1677. http://dx.doi.org/10.1002/macp.1985.021860815.

[31] P. Kolhe, R.M. Kannan, Improvement in ductility of chitosan through blending and copolymerization with PEG: FTIR investigation of molecular interactions, Biomacromolec. 4 (2003), 173-180. http://dx.doi.org/10.1021/bm025689+.

[32] N. Nwe, T. Furuike, H. Tamura, The mechanical and biological properties of chitosan scaffolds for tissue regeneration templates are significantly enhanced by chitosan from Gongronella butleri, Materials. 2 (2009) 374-398. http://dx.doi.org/10.3390/ma2020374.

[33] M.H. Periayah, A.S. Halim, N.S. Yaacob et al., Expression of P-selectin, TXA2, TGF- $\beta 1$ and PDGF-AB in the presence of bioadhesive chitosan derivatives, Online. Int. Interdiscip. Res. J. 4 (2014) 5-14.

[34] C.R. Correia, L.S. Moreira-Teixeira, L. Moroni et al., Chitosan scaffolds containing hyaluronic acid for cartilage tissue engineering. Tiss. Eng. Part C. 7 (2011) 17. 